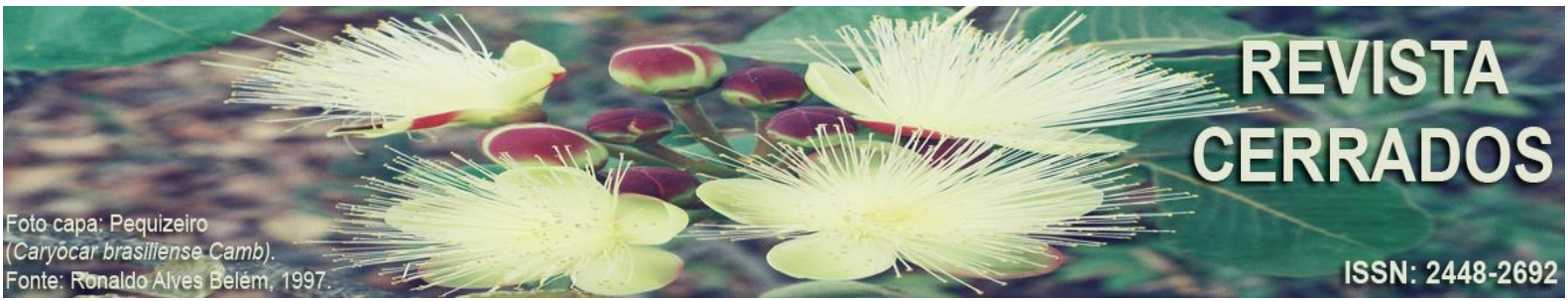

\title{
ANALISES DOS PADRÕES E ESTILOS DE CANAIS A PARTIR DA PAISAGEM GEOMORFOLÓGICA FLUVIAL NA BACIA DO RIO UNA/PE
}

\author{
ANALYSIS OF PATTERNS AND CHANNEL STYLE FROM THE \\ LANDSCAPE GEOMORPHOLOGICAL FLUVIAL IN RIVER BASIN \\ UNA/ PE
}

\section{ANÁLISIS DE PATRONES Y CANALES DE ESTILOS DE PAISAJE DEL RÍO GEOMORFOLÓGICO EN UNA DE CUENCA / PE}

\author{
Adriana Cassiano da Silva \\ Universidade Federal de Pernambuco - UFPE \\ E-mail: <dricacassiano@yahoo.com.br>. \\ Osvaldo Girão da Silva \\ Universidade Federal de Pernambuco - UFPE \\ E-mail: <osgirao@gmail.com>.
}

\begin{abstract}
Resumo
Os estilos fluviais refletem a fisiografia estrutural da rede de drenagem controladas pelos estratos rochosos, retratando na paisagem sua dinâmica, assim como os padrões de canais, que podem ser alterados por processos geomorfológicos, climáticos e antrópicos. O quadro dos estilos fluvial fornece um modelo geomorfológico dos processos espaciais e temporais biofísicos para gestão e planejamento das bacias hidrográficas. O presente trabalho teve como objetivo analisar as influências do comportamento no canal da bacia do rio Una localizado no Nordeste do Estado de Pernambuco, a partir da investigação das feições da drenagem como reflexo da transferência de matéria e energia entre distintos compartimentos e setores do ambiente fluvial. A metodologia proporcionou uma visão geral de toda área analisada, a partir da avaliação do índice de sinuosidade, mapeamento dos estilos e das feições fluviais, perfis longitudinais e trabalhos de observação em campo. Assim, constatou-se que a influência estrutural na rede de drenagem da referida bacia comandou a retilineidade do canal Una, com quebra no gradiente topográfico, inflexão do canal e vales encaixados. Nesse ambiente, verificou-se que a produção e deposição dos sedimentos estão vinculados as influências do clima tropical.
\end{abstract}

Palavras-Chave: Feição Fluvial; Estrutura; Instabilidade; Deposição de Sedimentos. 


\begin{abstract}
The river styles reflect the structural physiography drainage network controlled by the rock strata, depicting the landscape dynamics, as well as channel patterns, which can be changed by geomorphological, climatic and anthropogenic processes. The fluvial styles of the table provides a geomorphological model of spatial processes and biophysical time for planning and management of river basins. This study aimed to analyze the influence of behavior on the channel of the river basin Una located in the northeastern state of Pernambuco, from the investigation of drainage features reflecting the transfer of matter and energy between different compartments and sections of the river environment. The methodology provided an overview of the whole analyzed area, from the evaluation of the sinuosity index, mapping styles and river features, longitudinal profiles and field observation work. Thus, it was found that the structural influence on the basin drainage network commanded the straightness of Una channel, breaking the topographic gradient, channel inflection and enclosed valleys. In this environment, it found that the production and deposition of sediments are bound influences the tropical climate.
\end{abstract}

Keywords: Fluvial feature, structure, Instability, Deposition of Sediments.

\title{
Resumen
}

Los estilos de los ríos reflejan la red estructural de drenaje fisiografía controlado por los estratos de roca, que representa la dinámica del paisaje, así como los patrones de canal, que puede ser cambiado por procesos geomorfológicos, climáticos y antropogénicos. Los estilos fluviales de la tabla proporciona un modelo geomorfológico de los procesos espaciales y el tiempo biofísico para la planificación y gestión de las cuencas hidrográficas. Este estudio tuvo como objetivo analizar la influencia del comportamiento en el canal de la cuenca del río Una ubicada en el nororiental estado de Pernambuco, a cercar de la investigación de las características de drenaje que refleja la transferencia de materia y energía entre los distintos compartimentos y secciones del entorno del río. La metodología proporciona una visión general de toda la zona analizada, de la evaluación del índice de sinuosidad, la cartografía de estilos y características de ríos, perfiles longitudinales y trabajos de observación de campo. Por lo tanto, se encontró que la influencia estructural en la red de drenaje cuenca mandó la rectitud de canal Una, rompiendo el gradiente topográfico, la inflexión del canal y valles cerrados. En este entorno, se encontró que la producción y deposición de sedimentos están obligados influencias del clima tropical.

Palabras clave: Río de funciones; la estrutura; la inestabilidad; la deposición de sedimentos.

\section{INTRODUÇÃO}

Ao longo do século XX e início do século XXI houve o aumento da demanda para analisar as bacias hidrográficas, as quais as condições naturais estão vinculadas as ações 
antrópicas, cujas ações de planejamento geralmente apresentam ineficiência de gestão. Nesse caso, avaliar a paisagem de forma integrada a partir da investigação de subcompartimentos físicos da Terra, sob a vertente de seus diferentes níveis de conectividade permite um modelo mais autêntico para propor a qualidade funcional de seus ambientes.

Logo, analisar os sistemas fluviais vai além dos fluxos dos canais, mas sobretudo de toda a rede de drenagem, incluindo as porções de deposição (planícies, deltas e leques aluviais) e áreas formadoras de escoamento superficial e sedimentos. Para Chorley \& Kennedy (1971), os sistemas fluviais são constituídos por uma rede complexa de elementos que se associam e se ajustam às entradas (inputs) e saídas (outputs) de energia do sistema, cujos principais componentes físicos que se destacam dos sistemas fluviais são a (morfologia dos rios, planícies, encostas, entre outros) e o efeito cumulativo da interação água/sedimentos.

Dessa forma, caracterizar as feições fluviais viabiliza compreender se a rede de drenagem apresenta elementos controlados pela litoestrutura, pelo clima ou por ações antropicas. Ressalta-se que, as variáveis dos sistemas fluviais sofrem transformações tendendo a ajustes à novas condições de equilíbrio, sendo que, alguns sistemas se ajustam rapidamente ao rearranjo do relevo e outros obtém maiores resistências. Como corrobora Kondolf et al., (2003), os procedimentos de transformação no sistema fluvial operam por ajustes erosivo e deposicionais variando de um complexo ambiente para outro.

Dessa maneira, os sistemas fluviais diferem em escalas de tempo que vão desde pequenas transformações sazonais à alteração na vertente geológica por eventos tectônicos. Entretanto, as ações antrópicas alteraram significadamente importantes elementos na evolução do sistema fluvial, afetando, por exemplo, o nível de base, a taxa de sedimentação, a cobertura vegetal, assim como, a entrada e saída de energia no sistema alterando o balanço hidrodinâmico (Brierley \& Fryirs, 2005).

Nesse caso, o objetivo principal desse artigo é analisar o comportamento fluvial do rio Una, cujo vinculo tenha influência tectônica, do clima tropical, das ações antrópica ou comungando tais vertentes. Para tanto os objetivos específicos foram caracterizar os Estilos Fluviais (sinuosidade, declividade e tipo de vale), mapear os Estilos Fluviais e a Feições deposicionais, relacionar os padrões destes canais através do índice de sinuosidade e dos perfis longitudinais. 


\section{Caracterização da área}

A bacia hidrográfica do rio Una localiza-se em sua foz na porção sul do litoral pernambucano e na sua nascente no agreste meridional, possui uma área total de 6.740,31 $\mathrm{km}^{2}$, dos quais 477,53 km² estão no estado de Alagoas. A bacia abrange 42 municípios, a qual no município de Capoeiras está à nascente do rio Una, entre as serras da Boa Vista, com altitude de aproximadamente 900 metros e no município de Barreiros encontra-se sua foz (Figura 01). Alguns municípios da bacia do rio Una foram protagonistas de grandes calamidades públicas em 2010 com inundações que destruíram diversos municípios entre eles, Palmares, Água Preta, Barreiros e São José da Coroa Grande.

O rio Una possui extensão de 290 quilômetros, apresentando trechos intermitente até aproximadamente o município de Altinho e a partir dessa porção torna-se perene (APAC/2015). A área de estudo está inserida em quatro principais macrocompartimentos, quais sejam: a Planície fluvial a leste que contempla parte do baixo curso, após essa porção o Planalto Sedimentar Litorâneo, pois este o Piemonte da Borborema que abarca o médio curso e mais a oeste do piemonte, o Planalto da Borborema que está entre a porção do medio curso e na área total do alto curso do rio Una.

Figura 01 - Mapa de Localização

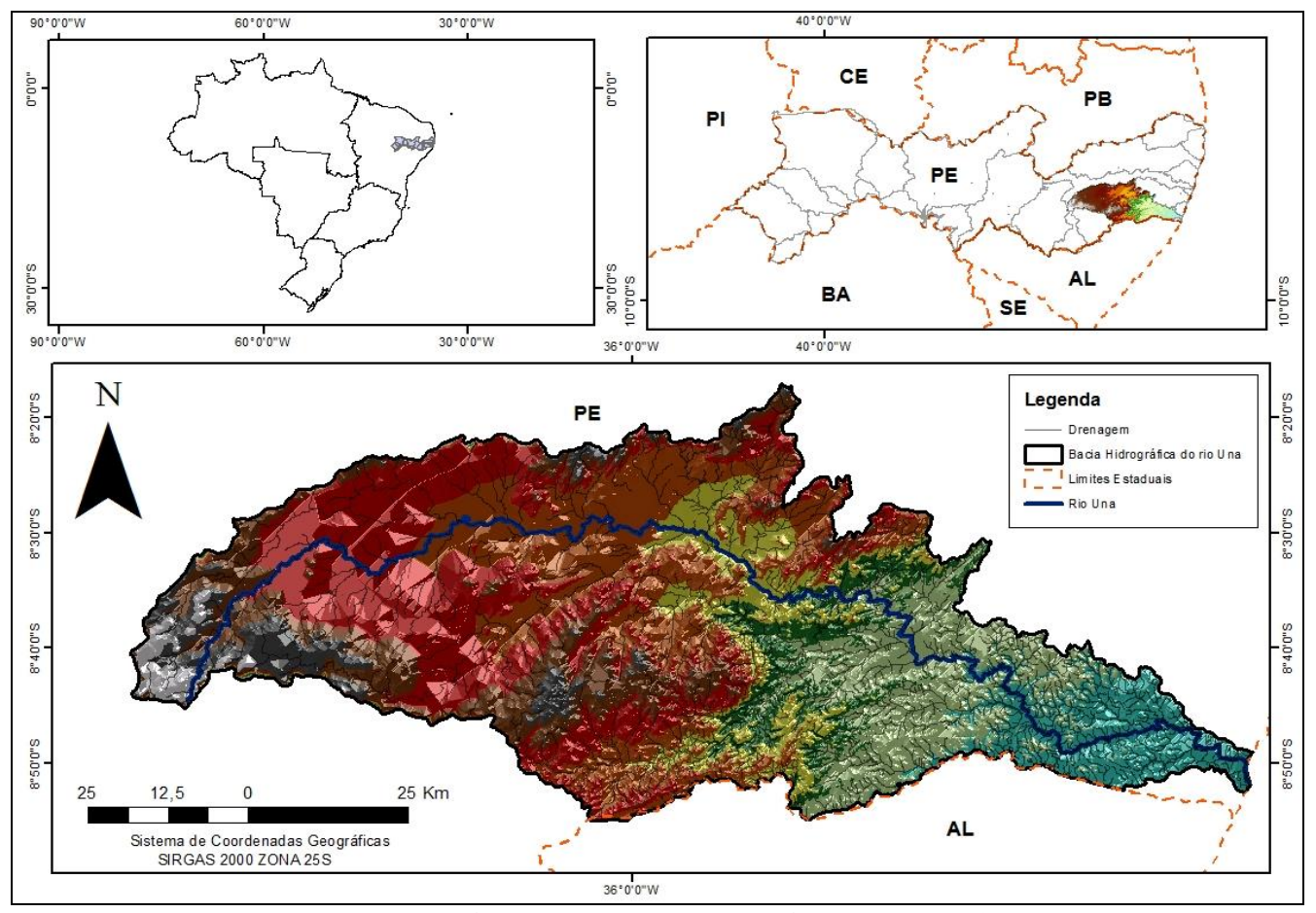

Fonte: IBGE e SRTM, adaptado por SILVA, A.C. (2016). 
A província da Borborema, termo usado por Almeida et al. (1977) compõe um conjunto de unidades geológicas estabilizadas no final da orogênese Brasiliana (NASCIMENTO, 2003). É um domínio geológico-estrutural localizado no Nordeste oriental do Brasil, limitado ao sul pelo Cráton de São Francisco, a oeste pela bacia do Parnaíba e a norte e a leste pelas bacias sedimentares da margem costeira (OLIVEIRA, 2008).

Representa um segmento crustal de uma extensa faixa fortemente afetada pela deformação Brasiliana Pan/Africana (600 - 50 Ma), denominada Faixa Trans-Saara, que resultou da colisão entre os crátons do oeste Africano/São Luiz e Congo-Kasai/São Francisco, a qual constitui massas continentais consolidadas em tempos pré-Brasilianos (JARDIM DE SÁ, 1994; BRITO NEVES et al., 2001 apud OLIVEIRA, 2008).

A evolução da Borborema no final do Neoproterozóico (Brasiliano-PanAfricano), foi marcado por uma expressiva abundância de intrusões graníticas, assinalando uma relevância marcante na história da orogênese Brasiliana (VAN SCHMUS et al., 2008 apud BRITO et al., 2009), sendo que, a maior parte delas estão associadas a zonas de cisalhamento NE-SW (ARCHANJO, 1993; JARDIM DE SÁ, 1994; NEVES e VAUCHEZ, 1995 apud BRITO et al., 2009).

A bacia do rio Una localiza-se ao sul do Lineamento Pernambuco, megacisalhamento destral que estão vinculados a compartimentação morfoestrutural da região, assim como seu arranjo tectônico ((BRITO NEVES et al, 2001a, 2001b, 2001c; ALMEIDA et $a l, 2000)$. Logo, este mega-cisalhamento rege importante comando na estrutura física do relevo possivelmente atrelado a pulsos tectônicos, que são marcados na configuração da rede de drenagem.

O domínio morfoestrutural se desdobra em unidades Morfológicas, nas quais as famílias das formas se baseiam nas relações geométricas encosta topo, altimetria e largura média dos divisores. Assim, esses atributos refletem a interação entre tectônica, litologia, estrutura superficial e os processos vigentes. A bacia do rio Una no sentido L-W apresenta Planícies Flúvio-marinhas, Planícies Fluviais, Planícies Costeiras e Planalto Sedimentar Costeiro, seguindo a oeste encontra-se as unidades geomorfológica dos Domínios de colinas Dissecadas, Domínios de colinas amplas e suaves, Modelado Tabular Dissecado e Conservado, Escarpa Dissecada e Cimeiras com cotas acima de 600 metros (CPRM, 2007).

Apresenta densa densidade de drenagem e seu arranjo espacial dos cursos fluviais constitui padrão de drenagem paralelo, ou seja, os cursos da água escoam quase paralelamente 
uns aos outros. Os solos que constituem a bacia do rio Una são os Planossolos, Regossolos, Vertissolos, Solos Litólicos, Podzólicos Distróficos, Latossolos Distróficos e Areias Quartzosas Marinhas, os quais são mais desenvolvidos na Zona da Mata Sul em decorrência principalmente da ação do clima (EMBRAPA, 2006).

A dinâmica climática que abarca o Nordeste está relacionada à atuação da massa Tropical Atlântica (Ta) e sistemas de perturbações atmosféricas secundárias que dinamizam as condições de tempo dominante, ocasionando instabilidades nos índices pluviométricos do litoral oriental do Nordeste, sendo estes os eventuais deslocamentos para o sul da Zona de Convergência Intertropical (ZCIT), a atuação da borda de Vórtices Ciclônicos de Altos Níveis (VCAN), Frentes Frias (FF), Distúrbios Ondulatórios de Leste (DOL) e Linhas de Instabilidades (LI) e, excepcionalmente a atuação da Zona de Convergência do Atlântico Sul (ZCAS), que são mecanismos de meso-escala (CAVALCANTI, et al., 2009).

Em relação ao Uso e Ocupação da Terra, a bacia do rio Una é composta de vastas áreas da cultura da cana-de-açucar, áreas urbanas e industriais, policultura e pecuária, acrescidas de áreas vegetadas com porte arbóreo fechada e espaçada, arbustivo-arbórea, manguezal e barramentos.

\section{METODOLOGIA}

Para o banco de dados em ambiente SIG, foram utilizadas imagens da TOPODATA produzidas nos dados do Shuttle Radar Topography Mission (SRTM), nas folhas SC-25-V-A e SC-24-X-B, com resolução espacial de 30 x 30 metros processados no software ArcGIS ${ }^{\circledR}$ 10.1. O datum e o elipsóide de referência em todos os produtos foi o SIRGAS 2000 Zona 25 sul, formato GeoTiff, disponibilizados no Banco de Dados Geomorfométricos do Brasil através do site do INPE.

Os procedimentos digitais permitiram produzir: Modelo Digital de Elevação (MDE), delimitação da área pesquisada, rede de drenagem e curva de nível. Na confecção do mapa geológico foi utilizado à base de dados da CPRM (2007), disponibilizados no site da CPRM. O trabalho de campo foi realizado em duas etapas, ambas para investigar e observar os estilos dos canais, as feições e averiguar o comportamento da rede de drenagem nos municípios de Palmares e Bonito. 
Para analisar e interpretar os estilos fluviais por meio da integração e espacialização dos diferentes tipos de canais, o presente estudo utilizou a metodologia de (River Styles, Brierley \& Fryirs, 2005). Destaca-se que em função da complexidade dos sistemas fluviais, um rio pode apresentar uma sucessão de distintos padrões de canais variando no tempo e no espaço. Davis (1898) analisou a classificação dos canais de acordo com o ciclo geológico em: jovens, maduros e senis. Para classificar a sinuosidade do canal Kellerhals et al. (1976), propôs subdividir o rio em segmentos, analisando suas mudanças dentro do seu trajeto (Figura 02).

Figura 02 - Classificação de canais fluviais: (1) reto; (2) sinuoso; (3) irregular; (4) meandros irregulares; (5) meandros regulares; (6) meandros tortuosos.

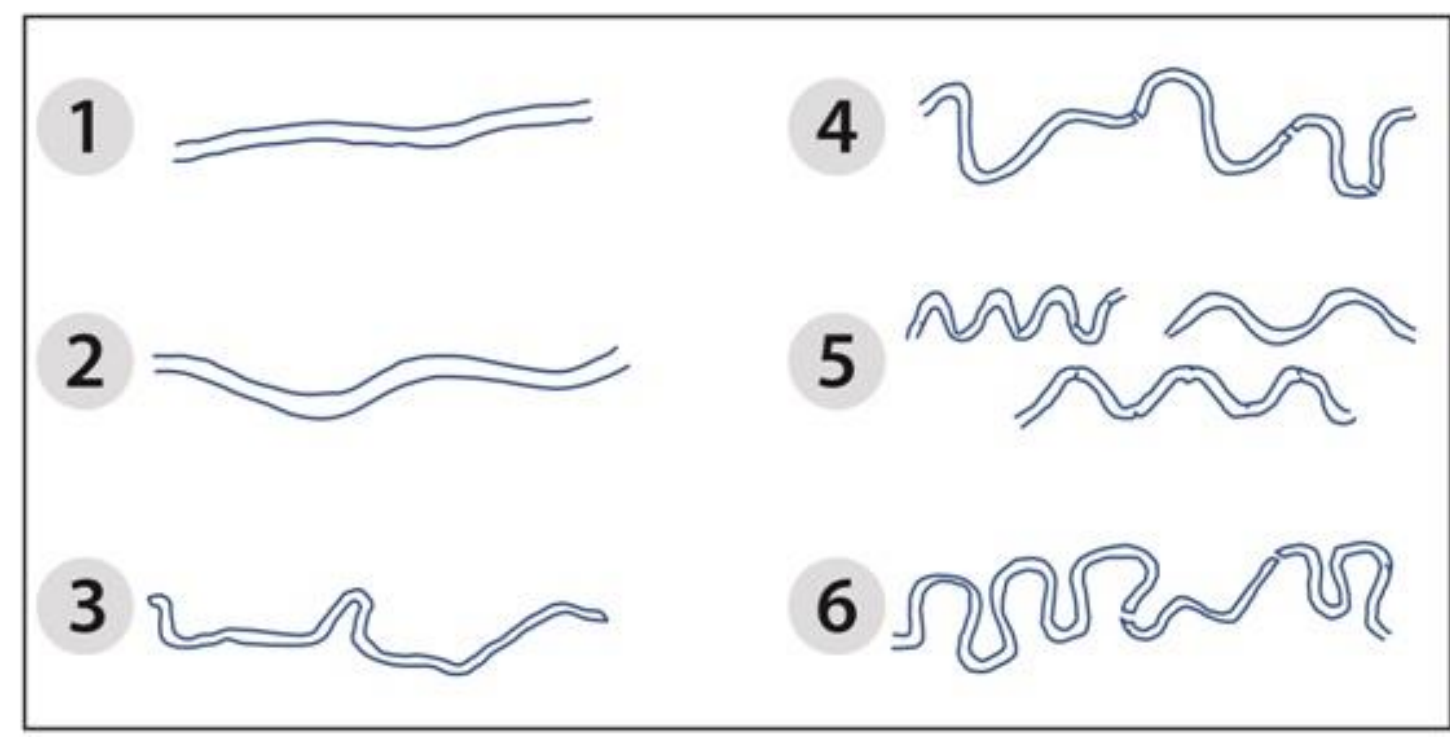

Fonte: Kellerhals et al. (1976)

Já Christofoletti (1981) classificou a tipologia dos canais em cinco morfologias individualizando cada feição (Figura 03). 
Figura 03 - Morfologia dos padrões de canal fluvial

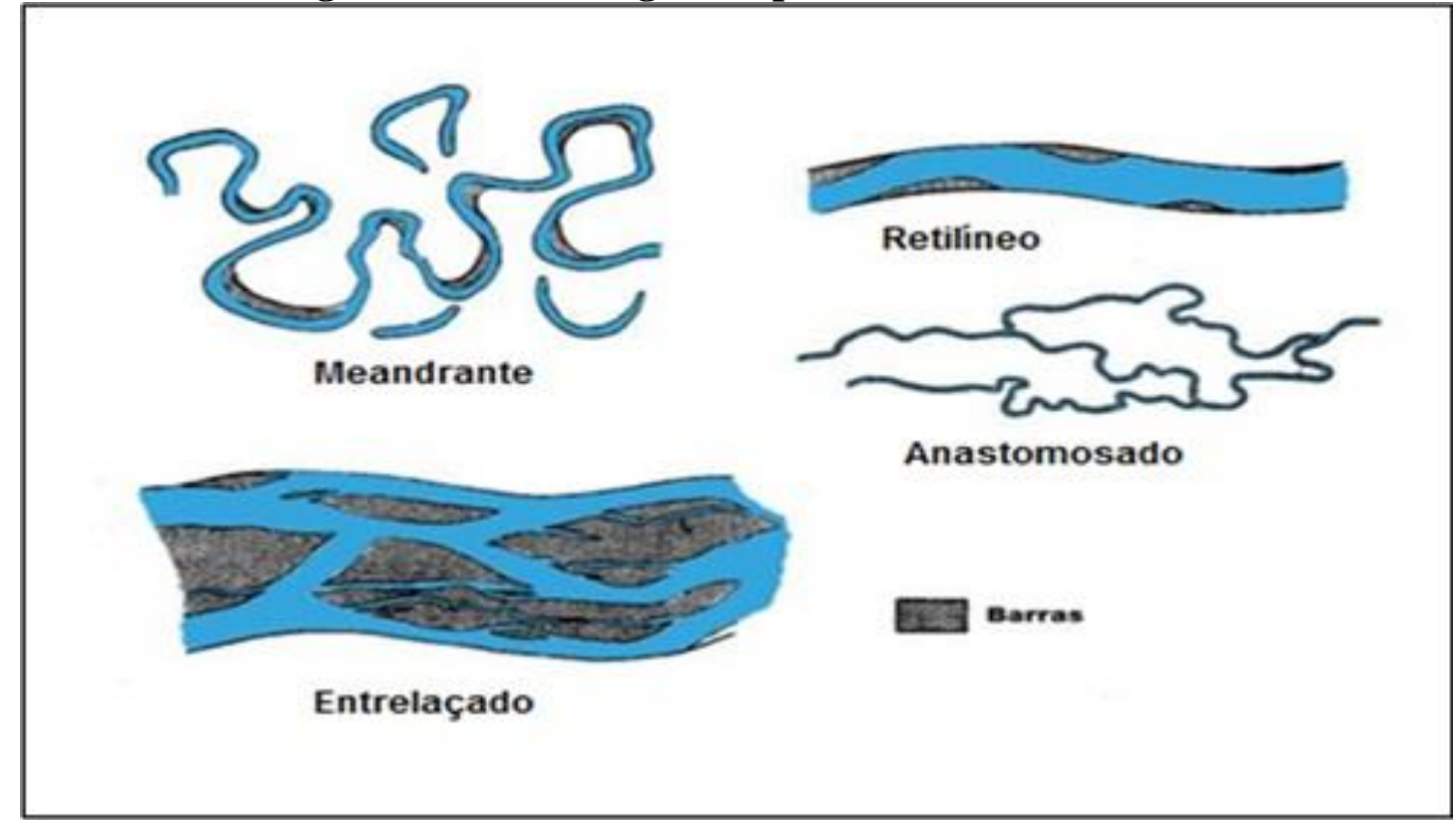

Fonte: Christofoletti (1981)

A partir desses procedimentos a presente pesquisa analisou a representação geométrica através do índice de sinuosidade e dos perfis longitudinais, assim como, o mapeamento dos estilos e feições fluviais para caracterizar o rio Una.

\section{Índice de Sinuosidade (IS)}

O índice de Sinuosidade é a relação entre a medida do trajeto real do canal e a medição em linha reta do rio entre a nascente e a foz. Os valores próximos a 1 indica que o canal tende a ser retilíneo e os valores superior a 2 sugere canais sinuosos (SCHUMM, 1981;2005). Encontram-se esses valores na fórmula:

$I s=\frac{L}{d v}$

Onde L é o comprimento do canal principal e dv é a distância vetorial entre os pontos extremos do canal principal (nascente e foz). Sabe-se que a sinuosidade dos canais pode ser influenciada pela carga de sedimentos, pela compartimentação litológica, pela estrutura geológica e pela declividade dos canais. 


\section{Perfil Longitudinal}

A elaboração dos perfis longitudinais de drenagem na bacia do rio Una foram baseados na metodologia de Christofoletti (1981) e das contribuições de Guedes et al (2006). O traçado do perfil longitudinal permite representar graficamente a interseção do canal, retratando a altimetria e o desnivelamento geométrico da drenagem, podendo está sob controle litoestrutural. Foram selecionados transectos no rio Una a partir dos segmentos do baixo, do médio e do alto curso, a fim de caracterizar o canal, as feições e os estilos fluviais.

\section{RESULTADOS E DISCUSSÃO}

O mapa geológico da bacia do rio Una demonstra distintas atividades no arranjo dos corpos geológicos, com enxames de diques e suíte magmática, que podem está condicionado por zonas de cisalhamento contracional, falhas e fraturas. Esta área situa-se próximo ao norte do Cráton do São Francisco, com faixas supracrustais neoproterozóicas marginais (pelítico-carbonáticas) e distais (vulcano-sedimentares), com exímios corpos de rochas graníticas brasilianas, denominado Maciço Pernambuco-Alagoas (Brito Neves et al., 2000; 2005). De acordo com França et al., (2015), essa porção é bordejado por falhas de empurrão com rochas de alto grau como gnaisses, migmatitos e granitos Brasilianos (Figura 04).

A estrutura geológica da área e o arcabouço de falhas, fraturas e cisalhamentos podem esclarecer e indicar o comportamento preferencial dos cursos fluviais e seu arranjo espacial, a partir da correlação litoestrutural no índice de sinuosidade, nas feições e estilos fluviais e nos transectos. 
Figura 04 - Mapa Geológico da bacia hidrográfica do rio Una

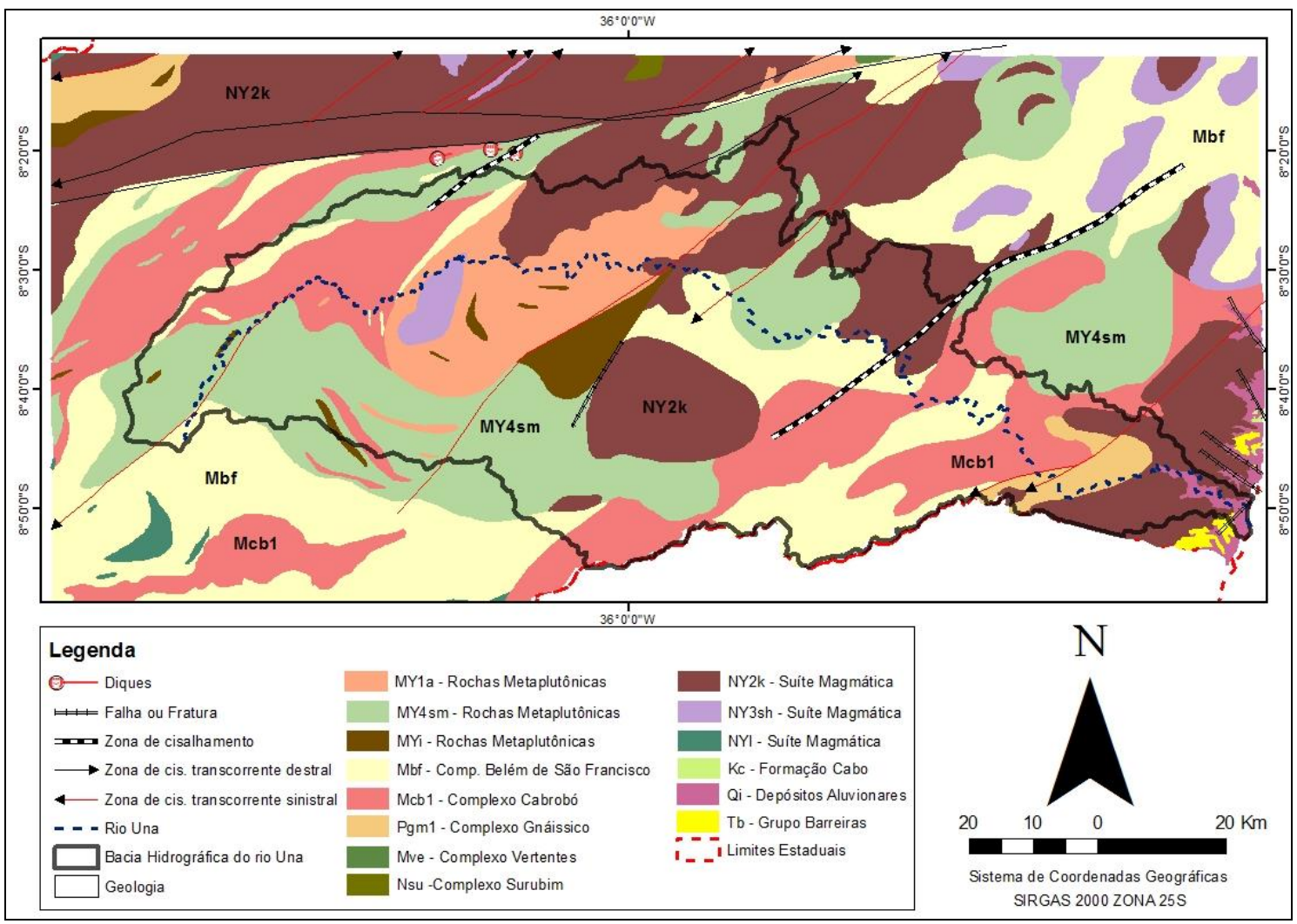

Fonte: CPRM, adaptado por SILVA, A.C. (2016).

\section{Índice de Sinuosidade (IS)}

A bacia hidrográfica do rio Una foi subdividida em baixo, médio e alto curso de acordo com a altimetria, cujos valores plotados para cada recorte apresentou índice de sinuosidade abaixo de 1, a qual indica que o canal tem tendência a ser retilíneo. Nesse caso, o índice de sinuosidade do canal Una sugere efeito de controle estrutural sobre a rede de drenagem que nesse viés, apresentou no baixo curso valor baixo para a sinuosidade, em que geralmente os canais nesse trecho apresentam contornos sinuosos mais aguçados, ou seja, conforme o método utilizado o rio Una retrata possível controle de herança tectônica. Sugerindo assim, que a sinuosidade do canal tem maior representação de quebra de gradiente como visto visualmente nas imagens de satélite do que sinuosidade permitida pelo arcabouço físico (Tabela 01). 
Tabela 01 - Valores do (IS) em distintos trechos do rio Una

\begin{tabular}{l|c}
\hline \multicolumn{1}{c|}{ Delimitação do rio Una } & Índice de Sinuosidade \\
\hline Baixo curso & 0,62 \\
\hline Médio curso & 0,62 \\
\hline Alto curso & 0,61 \\
\hline
\end{tabular}

Fonte: SILVA, A.C.

\section{Feições e Estilos fluviais}

A partir da avaliação do Índice de Sinuosidade, foram identificados seis segmentos distintos, sendo duas subdivisões no baixo, no médio e no alto curso do canal Una, apresentado na figura 05, para melhor visualização e interpretação das feições e estilos fluviais.

Dessa maneira, foi constatado no baixo curso do rio Una, no segmento 01 (parte inferior) e no segmento 02 (parte superior), o maior número de feições fluviais deposicionais, diferenciando-se conforme a declividade e a sinuosidade do canal em ilhas e barras laterais. A característica é de canal erosivo que transporta muitos sedimentos que se acumulam ao longo do canal. Neste trecho do baixo curso, os estilos fluviais foram predominantemente em sinuoso à irregular com deposição e vale confinado (Figura 06).

Esse aporte de sedimentos é intensificado no outono-inverno quando as feições dos canais são preenchidas pela sedimentação a montante. A permanência dessas feições nesse período ocorre em virtude da vegetação que se desenvolve e fixa seu tecido vegetal nas ilhas e nas barras.

Ressalta-se que o balanço erosivo e deposicional ao longo do canal fluvial e suas inter-relações com os fatores controladores e de conectividade são usados para interpretar o estágio evolutivo e a dinâmica, podendo verificar a influência geológica, geomorfológica, climática e antrópica no ambiente. Essa associação entre o balanço erosivo e deposicional e os fatores controladores podem resultar na migração de meandros, nas feições e nos estilos fluviais, nos fluxos de sedimentos, se referindo à influência do clima e a geomorfologia, bem como, na densidade de drenagem, em knick-points, na assimetria/simetria de talvegue, na mudança do nível de base, $n a$ anomalia de drenagem, quando relativo à estrutura litológica e 
ainda nos barramentos, soterramentos, mudança no fluxo hídrico, quando relacionado a ações antrópicas.

Figura 05 - Mapa da Subdivisão dos Segmentos do baixo, do médio e do alto curso na bacia hidrográfica do rio Una

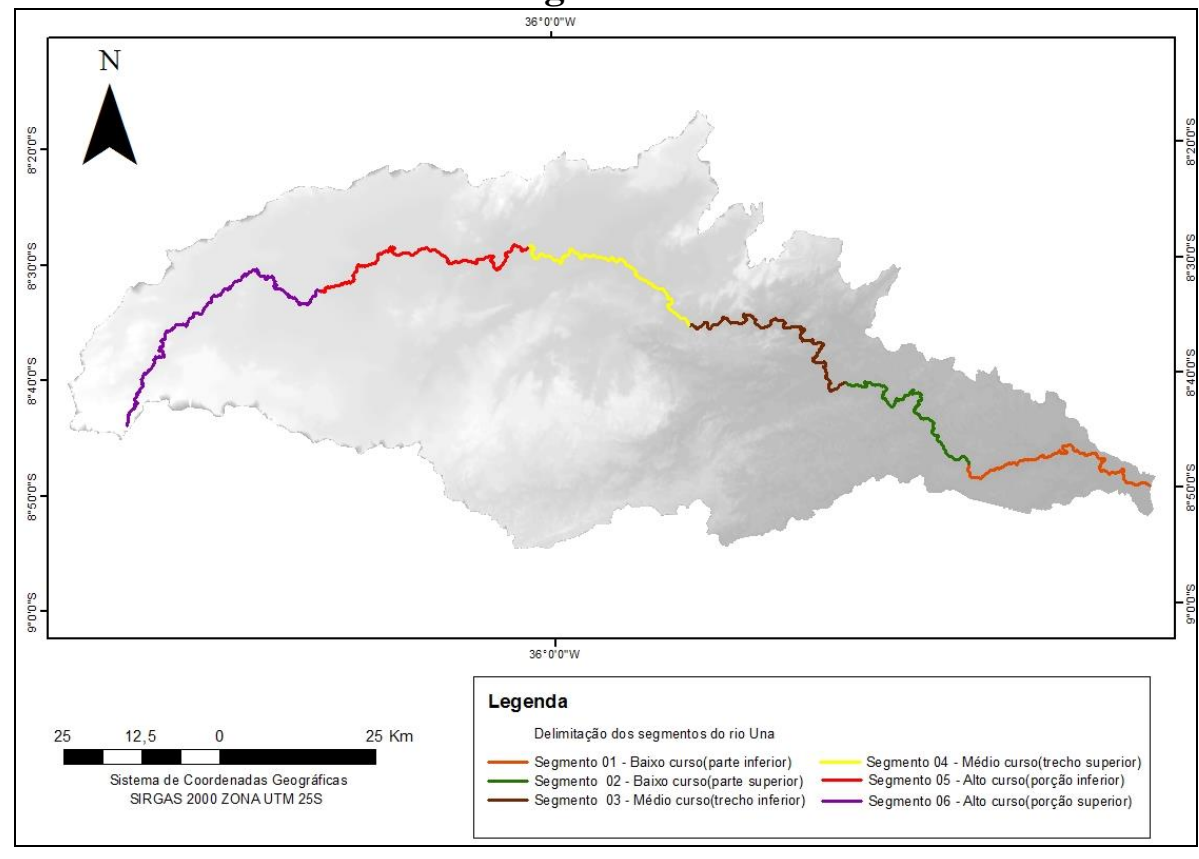

Fonte: SILVA, A.C. (2016)

Figura 06 - Mapa caracterizando as feições e estilos nos segmentos do baixo curso do rio UNA

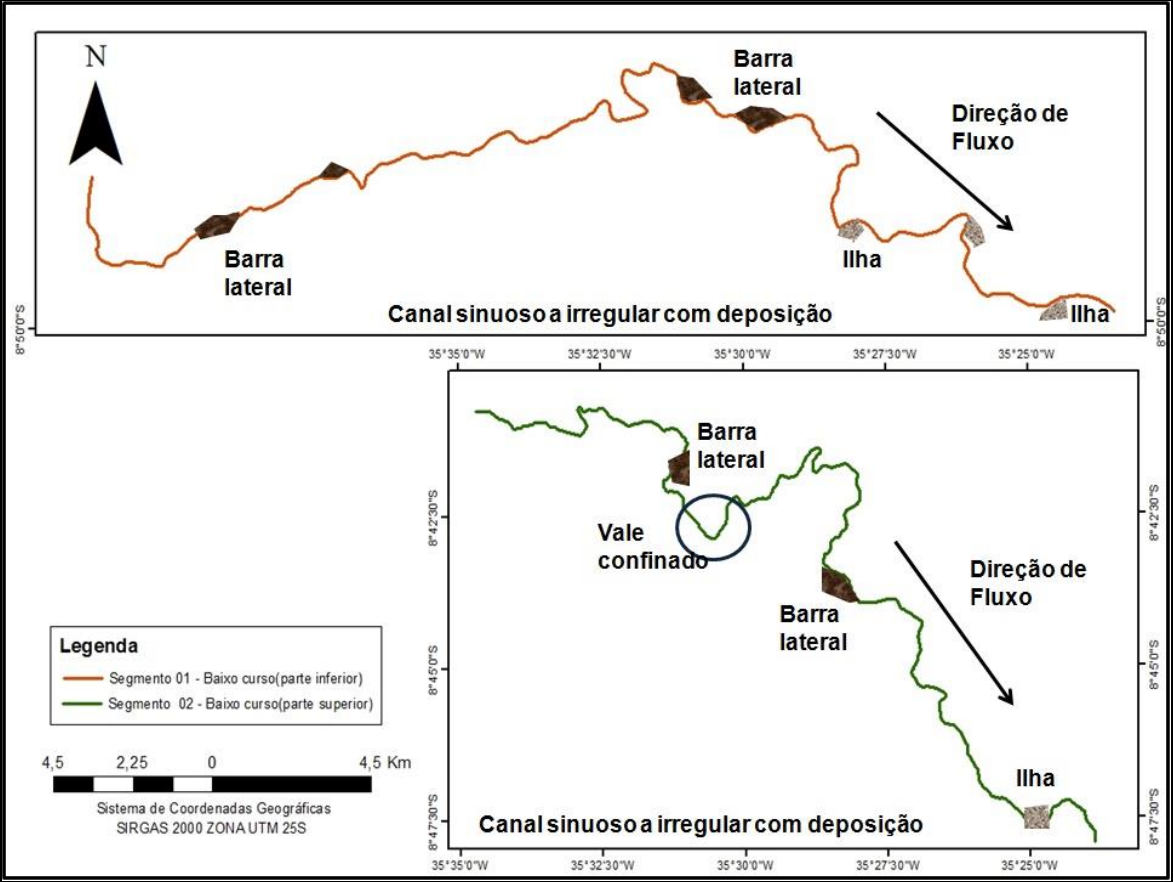

Fonte: SILVA, A.C. (2016) 
Logo, se destaca no baixo curso do Una as influências exógenas a partir da atuação do clima na produção e deposição dos sedimentos, alterando as feições fluviais, principalmente no período de maior intensidade pluviométrica, conforme visualizado na figura 07.

Figura 07 - Imagem das feições deposicionais no baixo curso do rio Una

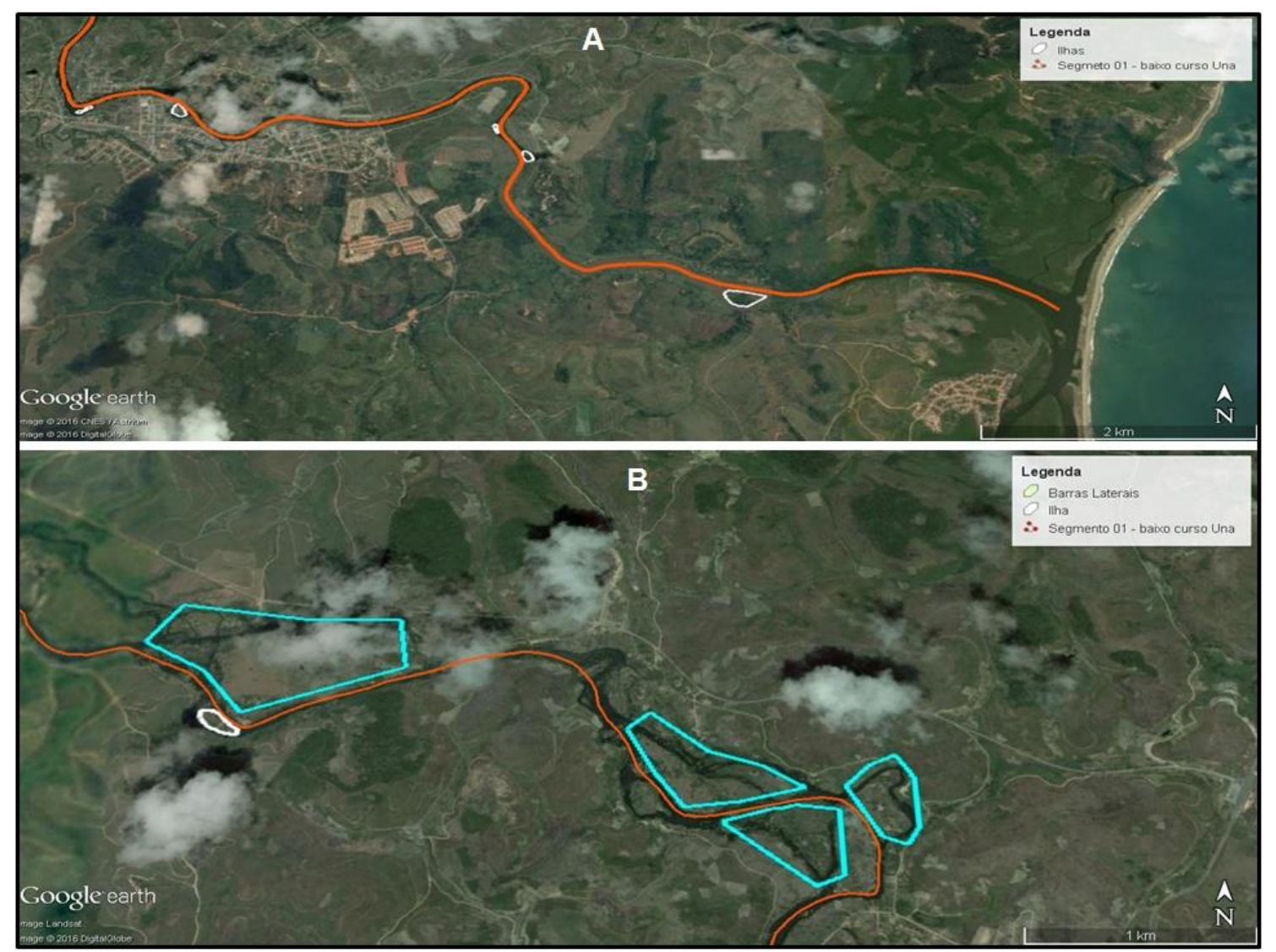

Fonte: Google Eath (2016)

No segmento 03 e 04 do médio curso do rio Una, a deposição se apresentou menos intensa, mas apresenta feição de ilhas e barras laterais. No segmento 03 (trecho inferior) há maior predominância na flexão do gradiente no canal e vale confinado retratando na paisagem o controle litoestrutural. O segmento 03 encontra-se no piemonte da Borborema e o segmento 04 (trecho superior) está na transição do piemonte para de fato o planalto da Borborema (Figura 08). 
Figura 08 - Mapa caracterizando as feições e estilos nos segmentos no médio curso do rio Una

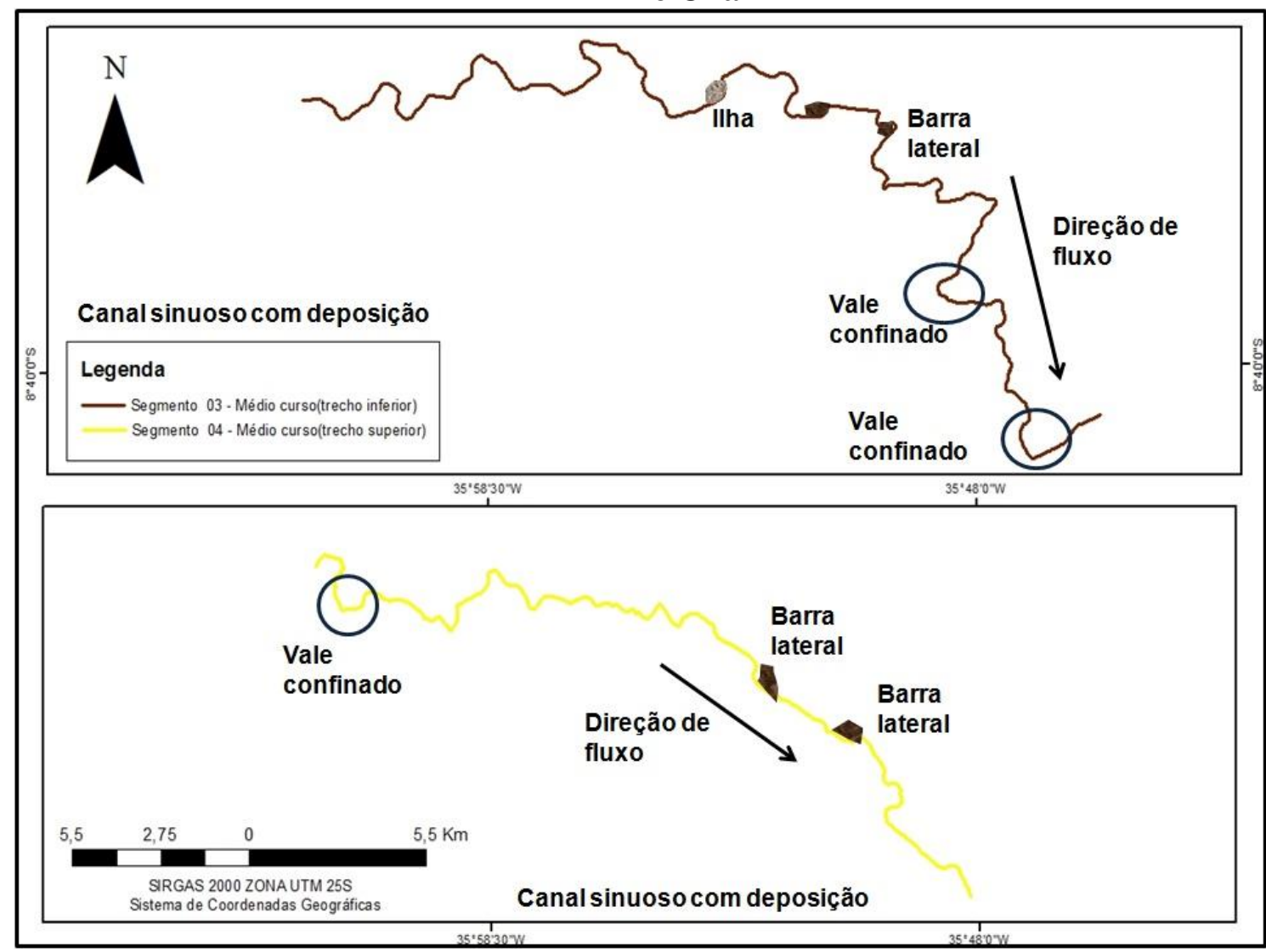

Fonte: SILVA, A.C. (2016)

Segundo Brierley \& Fryirs (2005), a influência do substrato rochoso determina a forma do rio e, quando associado a padrões de canal retilíneo, quebra de gradiente (corredeiras), com distribuição de piscina e canal confinado, possivelmente esses padrões de canais são respostas da drenagem a esforços estruturais encontrados na bacia estudada. Assim, o contexto geológico impresso na bacia do rio Una indica fortes características de controle estrutural que podem está vinculado a pulsos tectônicos, uma vez que, a área em questão apresenta um arcabouço com falhas, fraturas e cisalhamentos.

A figura 09 retrata o ambiente do médio curso no período do outono-inverno onde as feições deposicionais se mostram bastante vegetada e estabilizada no ambiente, entretanto, mesmo no período de grande volume hídrico se faz visível o substrato rochoso do rio Una. 
Figura 09 - Imagem com características pontuais no segmento 03, (médio cursomunicípio de Palmares): (a) barra lateral e ilha estável com vegetação; (b) ilha com vegetação; (c) e (d) substrato rochoso

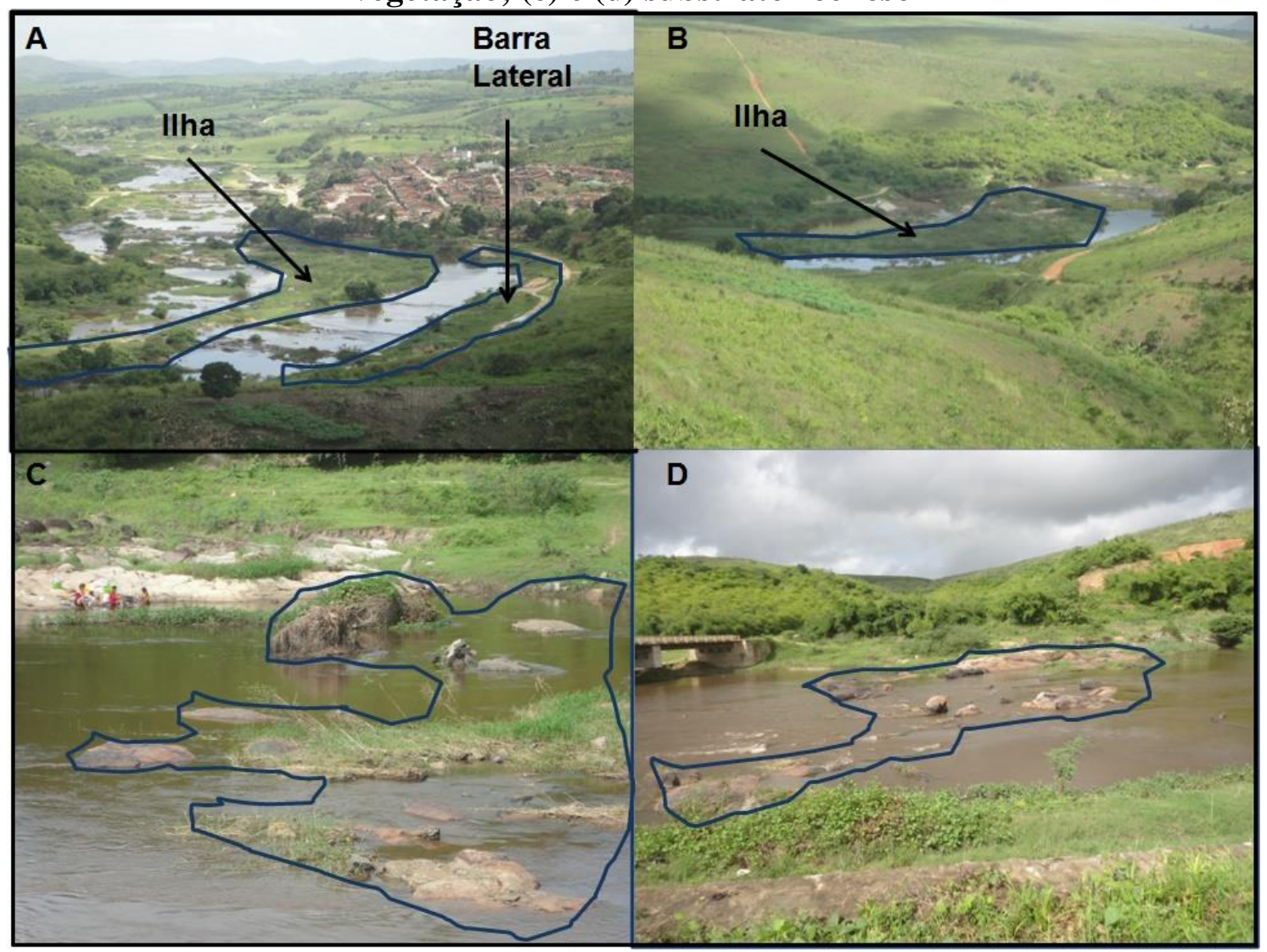

Fonte: SILVA, A.C. Tomadas em 2014.

No alto curso do rio Una, nos segmentos 05 e 06, não há feições deposicionais visíveis em imagens de satélites. Esse trecho retrata maior grau visual de controle estrutural em função da brusca inflexão do canal que corria na direção NNE e flexionou para SSE, bem como, outras flexões e vales confinados presentes nos segmentos. Nesse ponto, observa-se o entalhamento vertical em dois setores circulados em azul do segmento 05 e um no segmento 06, (Figura 10).

De forma geral, analisando cada segmento do canal Una observou-se que o mesmo apresenta uma planície fluvial estreita, a morfologia do canal varia de sinuoso a irregular, tendendo para retilíneo, indicando controle pelas linhas de falhas e fraturas, condicionados pela mega zona de cisalhamento ao norte da área, o Lineamento Pernambuco. Tal condição permitiria o equilíbrio na taxa de produção dos sedimentos, o que não confere a bacia do rio Una, em função do regime climático tropical permitir energia suficiente no sistema para retrabalhar e liberar sedimentos no ambiente. 
Figura 10 - Mapa caracterizando as feições e estilos dos segmentos no alto curso do rio Una

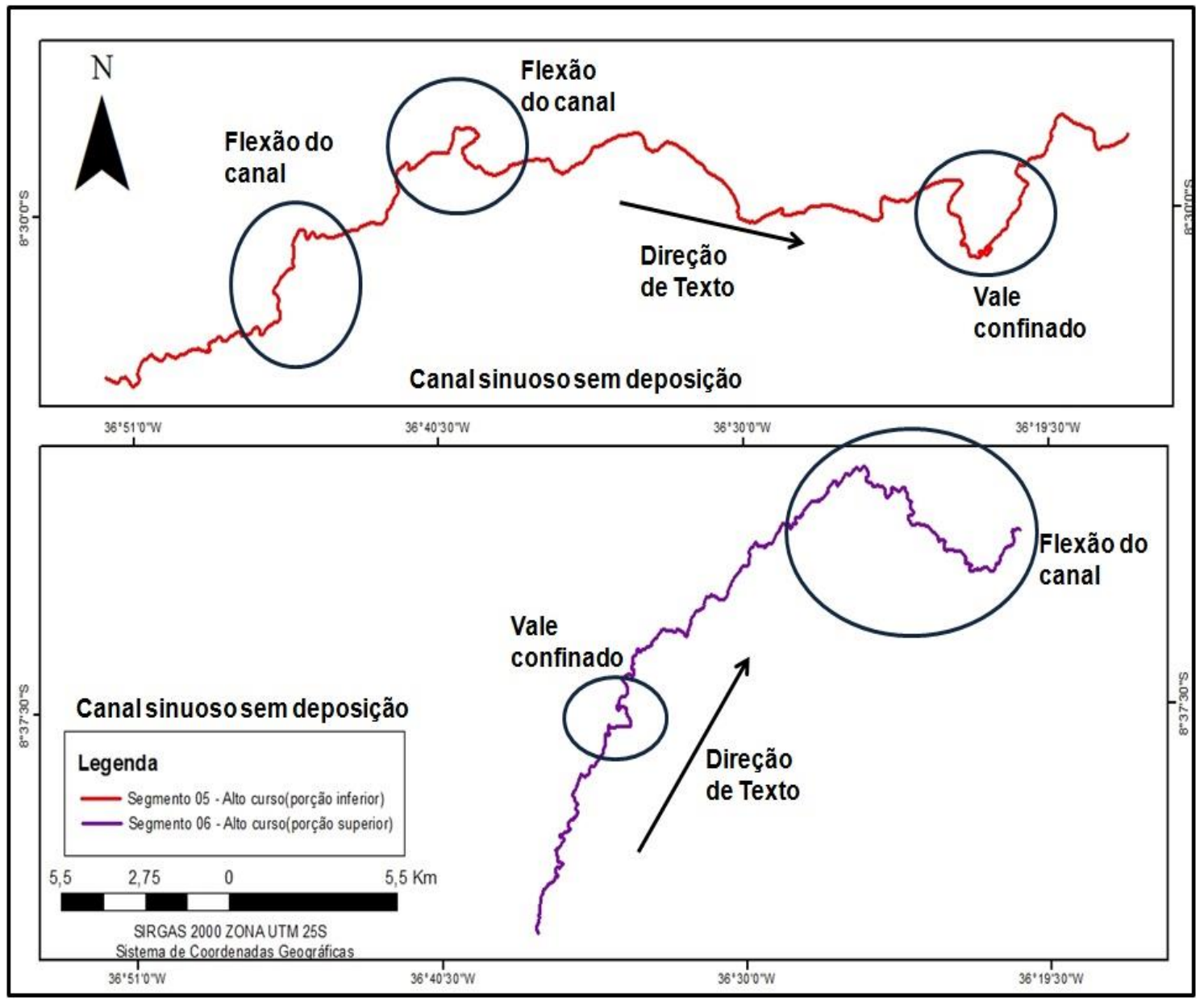

Fonte: SILVA, A.C. (2016)

Todo curso do rio Una é marcado por inflexão de canal, com mudança de gradiente por denudação ou agradação, em que alterou as condições de transporte visivelmente percebida entre o baixo, médio e alto curso modificando as feições deposicionais. A tabela 2 apresenta um agrupamento das feições e estilos caracterizados nos mapeamentos da referida bacia, para melhor compreensão integrada da mesma.

Tabela 02 - Características dos segmentos do rio Una

\begin{tabular}{l|l|l|l|l|l}
\hline \multicolumn{1}{c|}{ Segmento/ } & Estilo Fluvial & $\begin{array}{c}\text { Feição Fluvial } \\
\text { deposicional }\end{array}$ & Tipo de vale \\
\hline $\begin{array}{l}\text { L1 baixo curso- } \\
\text { parte inferior }\end{array}$ & $41,66 \mathrm{~km}$ & $30-100 \mathrm{~m}$ & $\begin{array}{l}\text { Sinuoso à à } \\
\text { irregular com } \\
\text { deposição }\end{array}$ & Ilhas e barras & Não confinado \\
\hline
\end{tabular}

Continua 
SILVA, A. C.; SILVA, O. G.

Analises dos padrões e estilos de canais a partir da paisagem geomorfológica fluvial na Bacia do Rio UNA/PE

\begin{tabular}{|c|c|c|c|c|c|}
\hline $\begin{array}{l}02 \text { baixo curso- } \\
\text { parte superior }\end{array}$ & $37,72 \mathrm{~km}$ & $100-150 \mathrm{~m}$ & $\begin{array}{lr}\text { Sinuoso } & \text { à } \\
\text { irregular } & \text { com } \\
\text { deposição } & \end{array}$ & Ilhas e barras & $\begin{array}{l}\text { Parcialmente } \\
\text { confinado }\end{array}$ \\
\hline $\begin{array}{l}03 \text { médio } \\
\text { curso-trecho } \\
\text { inferior }\end{array}$ & $47,00 \mathrm{~km}$ & $150-300 \mathrm{~m}$ & $\begin{array}{l}\text { Sinuoso com } \\
\text { deposição }\end{array}$ & barras & Confinado \\
\hline $\begin{array}{l}04 \text { médio } \\
\text { curso-trecho } \\
\text { superior }\end{array}$ & $38,65 \mathrm{~km}$ & $300-450 \mathrm{~m}$ & $\begin{array}{l}\text { Sinuoso com } \\
\text { deposição }\end{array}$ & Ilhas e barras & $\begin{array}{l}\text { Parcialmente } \\
\text { confinado }\end{array}$ \\
\hline $\begin{array}{l}05 \text { alto curso- } \\
\text { porção inferior }\end{array}$ & $48,67 \mathrm{~km}$ & $450-600 \mathrm{~m}$ & $\begin{array}{ll}\text { Sinuoso } & \text { sem } \\
\text { deposição } & \end{array}$ & $\begin{array}{ll}\text { Não } & \text { possui } \\
\text { deposição } & \end{array}$ & $\begin{array}{l}\text { Confinado, com } \\
\text { brusca inflexão do } \\
\text { canal }\end{array}$ \\
\hline $\begin{array}{l}06 \text { alto curso- } \\
\text { porção superior }\end{array}$ & $55,79 \mathrm{~km}$ & $600-900 \mathrm{~m}$ & $\begin{array}{l}\text { Sinuoso sem } \\
\text { deposição }\end{array}$ & $\begin{array}{ll}\text { Não } & \text { possui } \\
\text { deposição } & \end{array}$ & $\begin{array}{l}\text { Parcialmente } \\
\text { confinado, com } \\
\text { brusca inflexão do } \\
\text { canal }\end{array}$ \\
\hline
\end{tabular}

Fonte: SILVA, A.C. (2016)

\section{Perfil Topográfico do rio Una}

O perfil longitudinal de um rio corresponde ao alinhamento espacial do eixo do canal, permitindo observar e interpretar o comportamento da drenagem. Para que um perfil fluvial esteja em equilíbrio (graded) a forma deve estar côncava, podendo ser descrita por uma equação exponencial, dessa forma, se houver qualquer alteração na estrutura física do canal o fluxo hídrico procura se ajustar na busca de um novo equilíbrio, podendo erodir o leito ou propiciar agradação, curvas com menor concavidade indicam condições de desequilíbrio, conforme McKeownet al. Al., (1988 apud ETCHEBEHERE, M.L.C. et al., 2006).

Dentro da complexidade geotectônica da América do Sul, devem-se levar em consideração os eventos tectônicos de grande magnitude, como a ocorrência da reativação wealdeniana (ALMEIDA, 1967), bem como os processos que refletiram a "violência" desse evento em escala regional sobre o cristalino do Nordeste oriental, provocando desníveis consideráveis no relevo (MABESOONE, et al., 1975). Assim como, a flexura da borda da 
plataforma continental que se processou durante as fases rift e pós-rift, elaborando a formação de grábens e Horts na zona oriental do Nordeste, essa flexura ocorreu devido ao afinamento crustal no momento da separação dos continentes.

Nessa conjuntura, no desenvolvimento das bacias Pernambuco-Paraíba, Lima Filho el al., (2005), propõe uma sequência evolutiva cujo início ocorreu durante o Aptiano, na qual o Lineamento Pernambuco se movimenta na área afetada pelo rifteamento (bacia de Pernambuco), removendo a área rebaixada nos setores do Gráben de Olinda e o Gráben de Piedade. Já no Albiano, os esforços extensionais contínuos ocorreram nesta área com a presença de magmatismo. Essa trama de esforços extensionais pode ter sido projetados nos cursos fluviais do rio Una, uma vez que, o mapa geológico desta área indica a dinâmica dos processos nos corpos de diques, suítes magmáticas, possivelmente controlados pelos impulsos tectônicos na zona de cisalhamento, falhas e/ou fraturas.

A figura 11 demonstra nos transectos o controle estrutural no relevo da bacia do rio Una, visto que, nos perfis topográficos do baixo, médio e alto curso do Una, a drenagem corre paralela como constatada no padrão de dregnagem, com compartimentos nos canais sugerindo que a linha de descarga do Una acompanha possivelmente as linhas de fraquezas constituídas de falhamentos. Outra concepção desta área certifica que o canal não permite contorno meândricos aguçados em função do arcabouço rochoso.

Figura 11 - Perfil longitudinal em imagem SRTM nos segmentos do baixo, médio e alto curso do rio Una

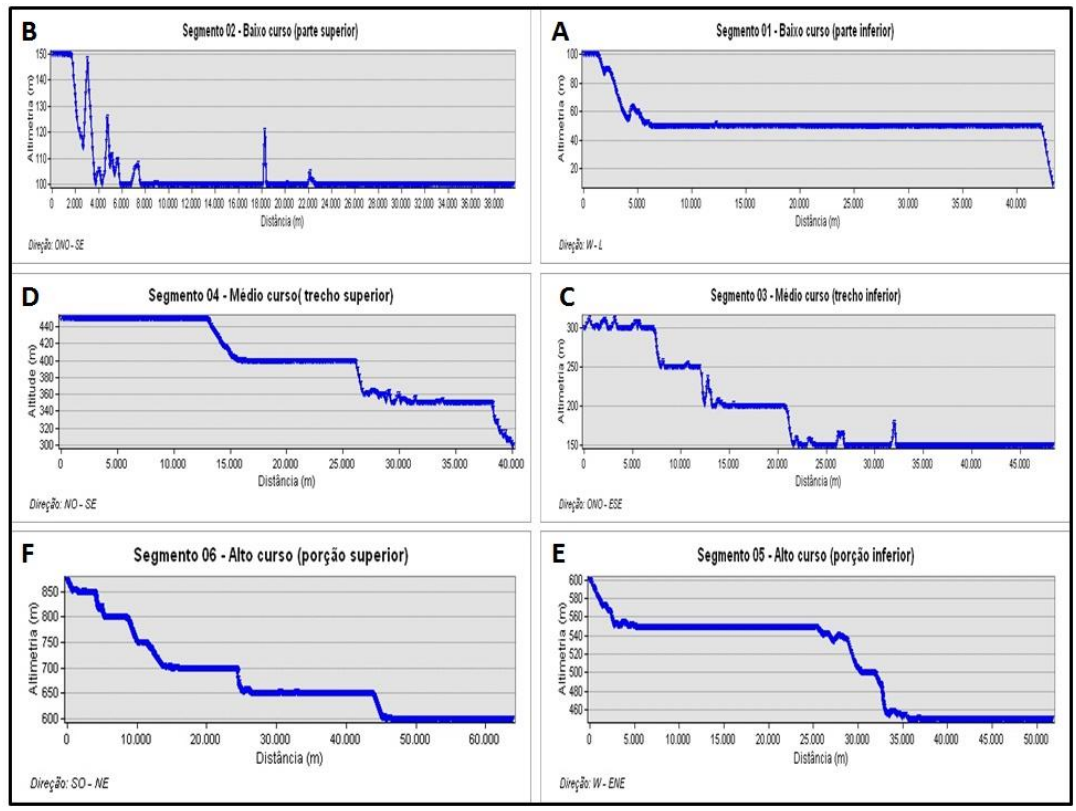

Fonte: SILVA, A.C. (2016) 


\section{CONCLUSÃO}

Os resultados demonstraram que a variação dos padrões no canal Una são controlados pela litologia, evidenciado no índice de sinuosidade, nos perfis topográficos e nos estilos fluviais. Assim como, na brusca inflexão do canal no médio e no alto curso, nos vales confinados e na tendência a retilineidade da drenagem.

Em relação às feições deposicionais em todo curso do Una, as mesmas estão relacionadas ao poder erosivo do canal com tracejo verticalizado, impulsionando a erosão, somado a isso, a influência dos inputs climáticos que alimenta o sistema fluvial na produção e disposição dos sedimentos. Esses depósitos ficam mais evidentes no baixo curso na forma de barras e ilhas, visto que, com a tendência morfológica do canal ser retilíneo a sinuoso, com baixa declividade permite a formação de feições diferenciadas.

A identificação dos estilos e as feições fluviais fornecem um quadro evolutivo e dinâmico dos padrões e taxas de sedimentos de cada compartimento avaliado, bem como, um modelo da capacidade dinâmica potencial de uma bacia hidrográfica em perda ou aumento na taxa dos sedimentos, nas circunstâncias de fluidez do canal, nas condições vegetacionais, entre outros. De forma geral, as análises discutidas nesse método busca fornecer um instrumento de gestão e planejamentos das bacias hidrográficas a partir da caracterização dos estilos e feições dos canais.

\section{REFERÊNCIAS}

ALMEIDA, F. F. M.; HASUI, Y.; BRITO NEVES, B. B.; FUCK, R. A. Províncias Estruturais Brasileiras. In: SIMPÓSIO DE GEOLOGIA DO NORDESTE, 8, Campina Grande - PB, Atas... Campina Grande: SBG, Núcleo Nordeste, 1977, p.363-391.

ALMEIDA, F. F. M.; LEONARDOS, O. H.; VALENÇA, J. Review on granitic rocks of Northeast South America. In: SYMPOSIUM ON NORTHEAST SOUTH AMERICA GRANITES, 1, 1967. Recife - PE. Resumes... Recife: IUGS/UNESCO, 1967, 41p. ALMEIDA, F. F. M., BRITO NEVES, B. B., CARNEIRO, C. D. R. The origin and evolution of the South American Platform. Earth-Science Reviews. 50, 2000. p. 77-111.

APAC - Agência Pernambucana de Águas e Clima. Bacias Hidrográficas. Disponível em: < www.apac.pe.gov.br>. Acesso dia 13 de dezembro 2015. 
BRIERLEY, G. J.; FRYIRS, K. A. Geomorphology and river management: applications of the river styles framework.Victoria: Blackwell Publishing (commerce place, 350 main street, Malden, may 02148, USA), 2005. 398p,.

BRIERLEY, G.J.; FRYIRS, K.A. The River Styles framework: The short course conceptual book. Macquarie Research Limited, 2003.

BRITO, M.F.L; FILHO, A.F.S., GUIMARÃES, I.P., Caracterização geoquímica e isotópica do batólito Serra do Catu e sua evolução da interface dos domínios Sergipano e PernambucoAlagoas, Província Borborema. Revista Brasileira de Geociências, Recife 2009. p. 324-337.

BRITO NEVES, B. B., CAMPOS NETO, M.C., VAN SCHMUS, W.R., SANTOS, E.J. O sistema Pajeú-Paraíba e o maciço São José do Campestre no leste da Borborema. Revista Brasileira de Geociências, v. 31. 2001 a. p. 1-15.

BRITO NEVES, B. B., CAMPOS NETO, M.C., VAN SCHMUS, W.R., FERNANDES, T.M.G., SOUZA, S. O terreno alto Moxotó no leste da Paraíba (maciço Caldas Brandão). Revista Brasileira de Geociências, v. 31. 2001 b. p.16-31.

BRITO NEVES, B. B.; VAN SCHMUS, W. R.; FETTER, A. H. Noroeste da África Nordeste do Brasil (Província Borborema): Ensaio comparativo e problemas de correlação. Revista do Instituto de Geociências - USP, série científica, v.1, 2001 c. p.59-78,

BRITO NEVES, B. B.; SANTOS, E. J.; VAN SCHMUS, W. R. Tectonic History of the Borborema Province. In: CORDANI, U. G.; MILANI, E. J.; THOMAZ FILHO, A.; CAMPOS, D. A . (Ed.). Tectonic evolution of South America. Rio de Janeiro: [s.n.], 2000. p.151-182.

BRITO NEVES, B. B.; VAN SCHMUS, W. R.; KOZUCH, M.; SANTOS, E.J.; PETRONILHO, L., A Zona Tectônica Teixeira Terra Nova - ZTTTN Fundamentos da Geologia Regional e Isotópica. Revista do Instituto de Geociências - USP Sér. Cient., São Paulo, v. 5, n. 1, 2005. p. 57-80.

CHORLEY, R.J. \& KENNEDY, B.A., Physical Geography: A Systems Aproach, London: Prentice Hall. 1971. 370p.

CHRISTOFOLETTI, A., Geomorfologia Fluvial. São Paulo: Edgard Blucher, 1981.

CAVALCANTI, I.F.A.; FERREIRA, N. J.; SILVA DIAS, M.A.F.; JUSTI DA SILVA, M. G. A. (Organizadores). Tempo e Clima no Brasil. Autores: vários. Editora: Oficina de Textos. ISBN: 9788586238925. Idioma: Português. Encadernação: Brochura. $1^{a}$ edição, 2009. 464p.

CPRM - Serviço Geológico do Brasil. Programa Levantamentos Geológicos Básicos do Brasil. Natal, Folha SB.25; Recife, folha SC.25. 2007.

DAVIS, W.M. The geographical cycle. Geographical Journal, 14(5), 1899. p. 481-504. 


\section{EMPRESA BRASILEIRA DE PESQUISA AGROPECUÁRIA - EMBRAPA. Sistema} brasileiro de classificação de solos. Rio de Janeiro: EMBRAPA/CNPS, $2^{\circ}$ ed., 306p. 2006.

ETCHEBEHERE, M. L. C.; SAAD, A.R..; FULFARO, V.J.; PERINOTTO, J.A.J., Detecção de Prováveis Deformações Neotectônicas no Vale do Rio do Peixe, Região Ocidental Paulista, Mediante Aplicação de Índices RDE (Relação Declividade-Extensão) em Segmentos de Drenagem.UNESP, Geociências, v. 25, n. 3, São Paulo, 2006. p. 271-287.

FRANÇA, R.H.M.; FERREIRA, V.P.; BEZERRA, J.P.S.; BIONDO, V.R., Contribuição da Gama Espectrometria ao estudo da Geologia do Batólito Águas Belas - Canindé: região a norte de Santana do Ipanema, Alagoas. XXVI Simpósio de Geologia do Nordeste, Anais, v. 26, 2015.

GUEDES, I. C.; SANTONI, G.C.; ETCHEBEHERE, M.L.C; STEVAUX, J.C. STEVAUX; MORALES, N.; SAAD, A.R., Análise de Perfis Longitudinais de Drenagens da Bacia do Rio Santo Anastácio(SP) para Detecção de Possíveis Deformações Neotectônicas. Revista UnG Geociências V.5, N.1, 2006, 75-102. 28p.

HACK, J. T. Stream-profile analysis and stream-gradient index. U.S. Geol. Survey, Jour. Research, Washington, v. 4, n. 1. 1973. p. 421-429.

KELLERHALS, R., CHURCH, M., BRAY, D.I., Classification and Analysis of river processes. Journal of Hidraulics Division, American Society of Civil Engeneers, 102: 1976, p. 813-829.

KLEINA,M., PAULA, E.V., SANTOS, L.J.C., Análises Comparativa dos Estilos Fluviais do rio Sagrado (Morretes/PR) para os anos de 2006 e 2011. Revista Geografar, Curitiba, v.9, n.1, 2014. p. 27-44.

KONDOLF, G.M.; MONTGOMERY, D.R.; PIEGÁY, H.; SCHMITT, L., Geomorphic Classification of Rivers and Streams. In: KONDOLF, G.M. \& PIEGÁY, H. Tools in Fluvial Geomorphology. 2003. p.171-204.

LIMA FILHO, M. F; BARBOSA J. A.; NEUMANN, V.H; SOUZA, E. M. Evolução estrutural comparativa da Bacia de Pernambuco e da Bacia da Paraíba. X Simpósio Nacional de Estudos Tectônicos e IV International Symposium on Tectonics of the Brazilian Geological Society. Curitiba- PR. 2005.

LIMA, R. N. S. Conectividade dos ambientes fluviais: implicações para avaliação da sensibilidade do sistema de drenagem da bacia do Rio Macaé (RJ). 2010. $128 \mathrm{f}$.

Dissertação (Mestrado em Geografia) - Departamento de Geografia, Instituto de Geociências, Centro de Ciências Matemáticas e da Natureza, Universidade Federal do Rio de Janeiro: Rio de Janeiro. 2010.

OLIVEIRA, R.G. Arcabouço Geofísico, Isostasia e Causas do Magnetismo Cenozóico na Província da Borborema e de Sua Margem Continental (Nordeste do Brasil). 2008. 415 f. Tese (Doutorado), Universidade Federal do Rio Grande do Norte: Natal. 2008. 
NASCIMENTO, M. A. L. Geologia, geocronologia, geoquímica e petrogênese das rochas ígneas cretáceas da província magmática do Cabo e suas relações com as unidades sedimentares da Bacia de Pernambuco, NE do Brasil. 2003. 235 f. Tese (Doutorado), Universidade Federal do Rio Grande do Norte: Natal. 2003.

MABESOONE, J. M.; CASTRO, C. Desenvolvimento geomorfológico do nordeste brasileiro. Boletim do Núcleo do Nordeste da Sociedade Brasileira de Geologia, Recife, n. 3, 1975. p.5-37.

SCHUMM, S. A. Evolution and response of the fluvial system: Sedimentologic Implications, SEPM, Special Publication, v. 31, 1981. p. 19-29.

SCHUMM, S. A. River Variability and Complexity. Colorado State University, 2005.

\section{Autores}

Adriana Cassiano da Silva - Possui Graduação e Mestrado pela Universidade Federal de Pernambuco (UFPE). Atualmente faz parte do Laboratório de Geomorfologia do Quaternário - LabGequa, Grupo de Estudo do Quaternário do Nordeste - GEQUA, da Universidade Federal de Pernambuco (UFPE).

Osvaldo Girão da Silva - Possui Graduação e Mestrado em Geografia pela Universidade Federal de Pernambuco (UFPE); Doutorado em Geografia pela Universidade Federal do Rio de Janeiro (UFRJ). Atualmente é professor do Departamento de Ciências Geográficas da Universidade Federal de Pernambuco (UFPE).

Artigo recebido em: 26 de julho de 2016

Artigo aceito em: 19 de outubro de 2016 